\title{
Time-Resolved Tomographic Images of a Relativistic Electron Beam
}

\author{
H. A. Koehler, B. A. Jacoby, and M. Nelson
}

This paper was prepared for the Proceedings of the Society of Photo-Optical Instrumentation Engineers

August 19-24, 1984

San Diego, CA

July 1984

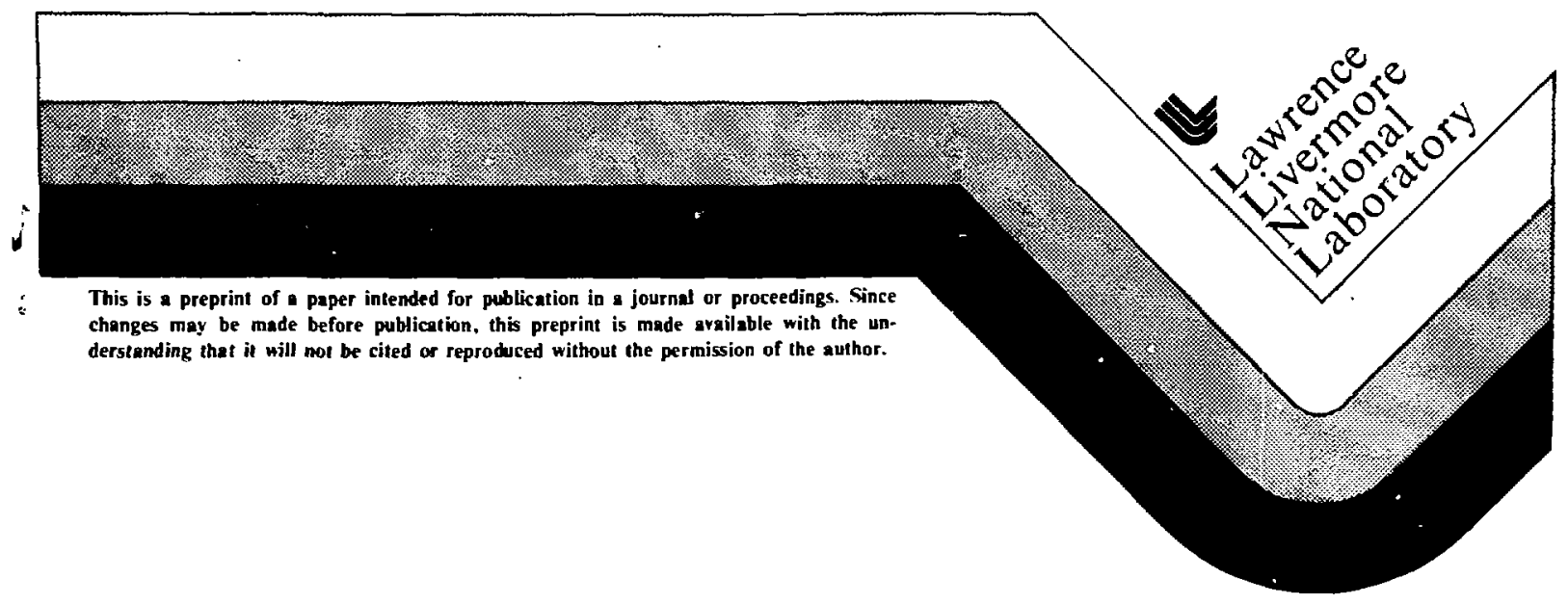


Time-resolved tomographic images of a relativistic electron beam*

11. A. Kixhler dand B. A Jacoby

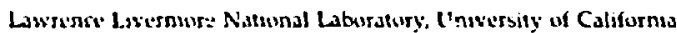

P.O. Bux E0X, Livermore. Califurnia 94550

M. Nelsun

EG\&G. Inc.. Santa Barbara Operati ins

130 Rubin Hill Roud, Goletu, Colifornia 93117

\begin{abstract}
We ubtained a sequential series of time-resolved tomographic two-dimensional images of a 4.5-MeV, 6-kA. 30-ns elk. tron beam. Three linear fiber-uptic arrays of 30 or 60 fibers each were positioned around the beam axis at $0^{\circ}, 61^{\circ}$, and $117^{\circ}$. The beam interacting with nitrogen at 20 Torr emitted light that was focused onto the fiber arrays and transmitted to a streak camera where the data were recorded on film. The film was digitized, and two-dimensional images were seconstructed using the maximum atropy tonographic technique. These images were then combined to produce an ultra-high-speed movie of the electron-beam put e.

\section{$\underline{\text { Introduction }}$}

We have developed a diagnostic system using optical-fiber links to monitor the propagation of relativistic electron beams in the Experimental Test Accelerator (ETA) at Lawrence Livermore National Laboratory. Our diagnostic system usi's a three-vjew: tomographic imaging scheme to observe luminescence produced by electron-beam interactions with nitrogen. Light emissions are focused onto linear arrays of optical fibers and transmitted to a streak camera where they are recorded by a solid state camera $:$ on photographic film. The data are then analyzed by computer to reconstruct a two-dimensional tomographic image frum the thre onedimensional images.
\end{abstract}

By using a streak camera to record the data, ${ }^{1}$ we were able to reconstruct a sequential series of images of the electron bearn having 1-ns time resolution. Using these images, we then produced an ultra-high-speed movie of a selativistic electron-beam pulse from the ETA passing through nitrogen gas at 20 Torr.

The use of optical fibers to transmit the signals from the beam to the recording room allowed not only great flexibility in our experimental arrangements, but it enabled us to place the sensitive recording instrumentation away from the large background radiation associated with the $4.5-\mathrm{MeV}, 6-k$ A ETA electron-beam pulse.

\title{
Experiment
}

The major components of the experimental arrangement were three linear arrays of optical fibers mounted in three sampling heads and a streak camera recording system.

\section{Sampling heads}

Three sampling heads were positioned at $0^{\circ}, 61^{\circ}$, and $117^{\circ}\left(0^{\circ}\right.$ being the top position) in a plane perpendicular to the 6-in.diameter plastic drift tube of the ETA (Fig. 1). The mounting bracket was placed $2 \mathrm{ft}$ from the entrance foil separating the accelerator section from the drift tube section and $6 \mathrm{ft}$ from the beam dump. The distance of $\mathrm{t}$. ' sampling heads from the tube axis was about $3 \mathrm{ft}$. Each head observed a one-dimensional region about $4.3 \mathrm{in}$. long and oriented perpendicular to the drift tube, which corresponds to spatially resolved regions 0.07 and $0.14 \mathrm{in}$. long per fiher for the 60 - and 30 -fiber linear arrays, respectively.

Standard camera lenses (40-mm fical length, $/ 11.8$ ) were used to focus the electron-beam-induced emission from the nitrogen gas onto the linear array of optical fibers. Inclications are that the emission occurred at $391 \mathrm{~nm}$. (At this wavelength, the lens transmission was abuut 0.5.)

\section{Optical fibers}

The (pptical fibers used in our optical electron-beam diagnostic sustem were selected on tive basis of three criteria: 1) low attenuation in the near-UV wavelength region of the nitregen emission lines. 2) high bandwidth for undistorted transmission of subnanusecond signals, and 3) minimum susceptibility to electron. gamma-, and x-ray- damage. We evaluated a number of optical fiber types on the basis of these three properties (Table 1 1. ${ }^{2}$ Test fibers were 50 -ft lengths appropriate to ETA optical diagaustic systems.

\footnotetext{
- This work was performed under the auspices of the U.S. Department of Enengy hy Lawrence Livermore National Labo: ztory under Contran W.-705-Eng-48 und for the U.S. Department of Defense under Defense Attvanced Research Projects Agency. DARPA Onder No. 4395 A \#12. monitured by the Naval Surface lieapons Center.
} 


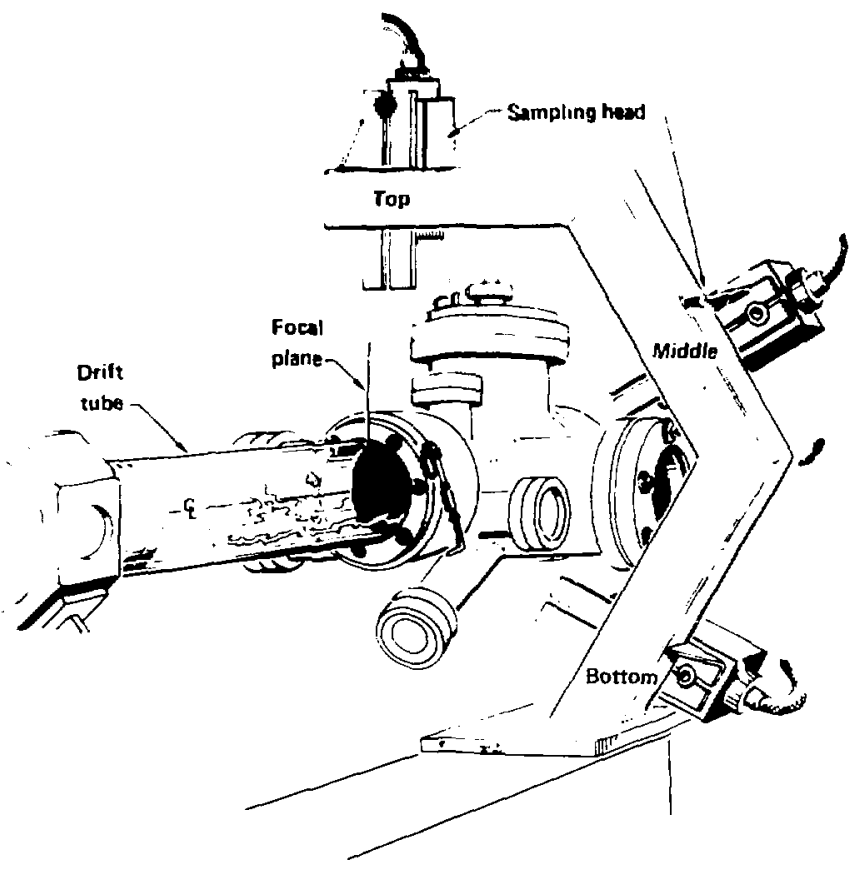

Figure 1. Configuration of the diagnostic system to monitor the propagation of relativistic electron beams in the Experimental Test Accelerator. The three sampling heads were positioned at $0^{\circ}, 61^{\circ}$, and $117^{\circ}$ in a plane perpendicular to the drift tube. Each head observed a one-dimensional region perpendicular to the drift tube.

Table 1. Bandwidth, attenuation, and radiation responses of selected 50-ft-long fibers at UV wavelengths.

\begin{tabular}{|c|c|c|c|c|c|c|c|}
\hline Fiber & $\begin{array}{c}\text { Core/clad } \\
\text { diameters } \\
(\mu \mathrm{m})\end{array}$ & Type & $\begin{array}{c}\text { Numerical } \\
\text { aperture }^{b}\end{array}$ & $\begin{array}{c}\text { Impulse } \\
\text { respanse } \\
\text { (ps) }\end{array}$ & $\begin{array}{l}\text { Attenuation }{ }^{\mathrm{d}} \\
\text { (dB) }\end{array}$ & $\begin{array}{c}\text { Radiation } \\
\text { response" } \\
\text { (dB/cm.krad) }\end{array}$ & Comments \\
\hline QPC QSF-AS & $163 / 200$ & $\mathrm{G}-\mathrm{G}$ & 0.2 & 460 & 4.8 & 0.007 & $1200 \mathrm{ppm} \mathrm{OH}$ \\
\hline QPC QSF-AS & $135 / 200$ & $\mathrm{G}-\mathrm{G}$ & 0.2 & 560 & 16.9 & - & $1200 \mathrm{ppm} \mathrm{OH}$ \\
\hline QPC QSF-UV & $200 / 380$ & PCS & 0.4 & 600 & 2.4 & 0.008 & - \\
\hline QPC QSF-LV & $400 / 550$ & PCS & 0.4 & 620 & 2.4 & - & - \\
\hline QPC QSF-UV & $600 / 750$ & PCS & 0.4 & 680 & 2.2 & - & - \\
\hline QPC QSF-A & $200 / 380$ & PCS & 0.4 & 600 & 2.6 & 0.008 & - \\
\hline ITT PS-05 & $125 / 300$ & PCS & 0.3 & 900 & 2.9 & - & - \\
\hline ITT T-1210 & - & PCS & - & 540 & 11.8 & - & - \\
\hline Dupont Pifax 5-120 & $200 / 600$ & PCS & 0.42 & 1400 & 3.8 & - & - \\
\hline Times & - & PCS & - & 460 & 8.7 & - & - \\
\hline
\end{tabular}

${ }^{\circ} \mathrm{G}-\mathrm{G}$ is glass-on-glass; PCS is plastic-clad silica.

"Numerical aperlures were not measured, and the values given are those supplied by the manufactures.

'Measured response to a 300-ps full width at half-maximum $337-\mathrm{nm}$ laser pulse. The svstem response wras $460 \mathrm{ps}$

Attenuation was measured at $340 \mathrm{~nm}$.

e Radiation response was mieasured at $350 \mathrm{~nm}$.

Attenuation measurements were made at $340 \mathrm{~nm}$ using a white light source, a narrowband filter, and a radiometer. The standand measure-and-cutback technique was used.

Bandwidth evaluations were made at $337 \mathrm{~nm}$ using a nitroger laser emitting 300 -ps pulses and 2 vacuum photodiodeI ascilloscope recording system with a 400 -ps impulse response. 


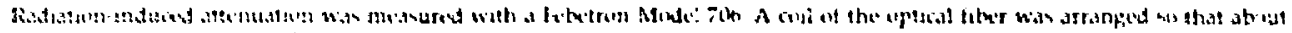

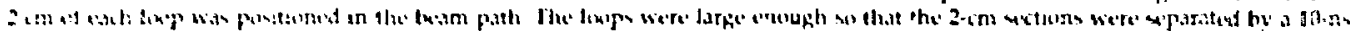

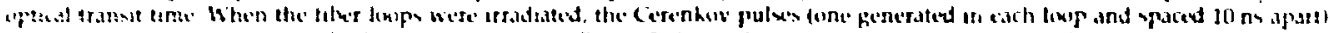

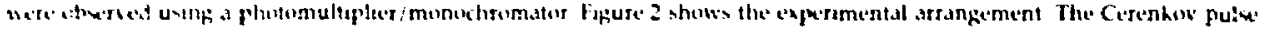

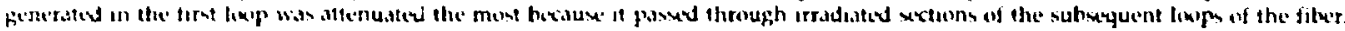

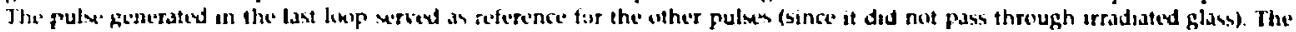

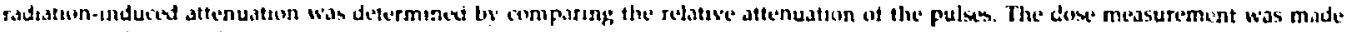
unin: radiuhrumic silm

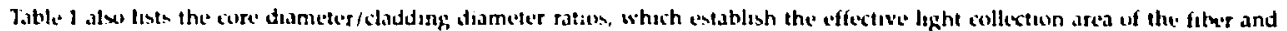

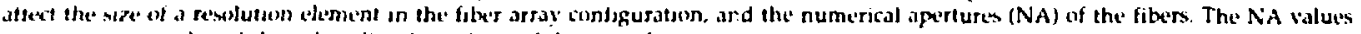
were not medsured. and the values listed are those of the manufacturer.

On the biss of the medsurements, wo ty pes of fibers were selected: QSF-AS and QSF-UV. The QSF-AS fiber has 4.8-dB attenuatun at $390 \mathrm{~nm}, \quad 450 \cdot \mathrm{ps}$ impulse response, 1$) 007-\mathrm{dB} / \mathrm{cm} \cdot \mathrm{krad}$ radiatien response at $350 \mathrm{~nm}$, core/cladding diameters of 163

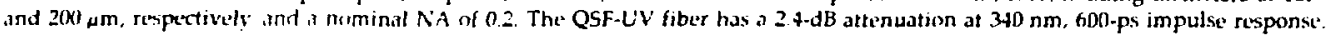
core/cladding diameters of 200 and $380 \mu \mathrm{m}$, respectively, and a nominal NA of 0.4. The QSF-AS fibers were arranged into one 12$\mathrm{mm}-\mathrm{long}$ linear array of 60 fibers, and the QSF-UV fibers were arsanged into two 12 -mm-long linear arrays of 30 fibers each. Both ends of each linear array were munted intu plastic blocks.

\section{Streak camera recording sistem}

A streah camera recording system was used to record time-resolved beam profiles. The three !inear fiber array's were aligned perpendicular to the streak direction and focused with 3:1 reduction onto the slit area of a 675 Hadland streak camera. The micreshannel piate intensifier output of the streak camera was recorded with a Reticon $100 \times 100$ photodiode array and stored an a floppy disk or, when greater resolution was desired, the intensifier output was recorded on Kodak 2484 film. When film was used, the spatial resolution was $1.6 \mathrm{in}$. of the beam $/ \mathrm{mm}$ of $\mathrm{film}$, and the temporal resolution was $3.6 \mathrm{~ns} / \mathrm{mm}$ of film. The streak camera photecathode with 7 line pair $/ \mathrm{mm}$ limited the system's resolution. The corresponding resolution was about 45 elements per fiber optic array (using a $12-\mathrm{mm}$-wide slit).

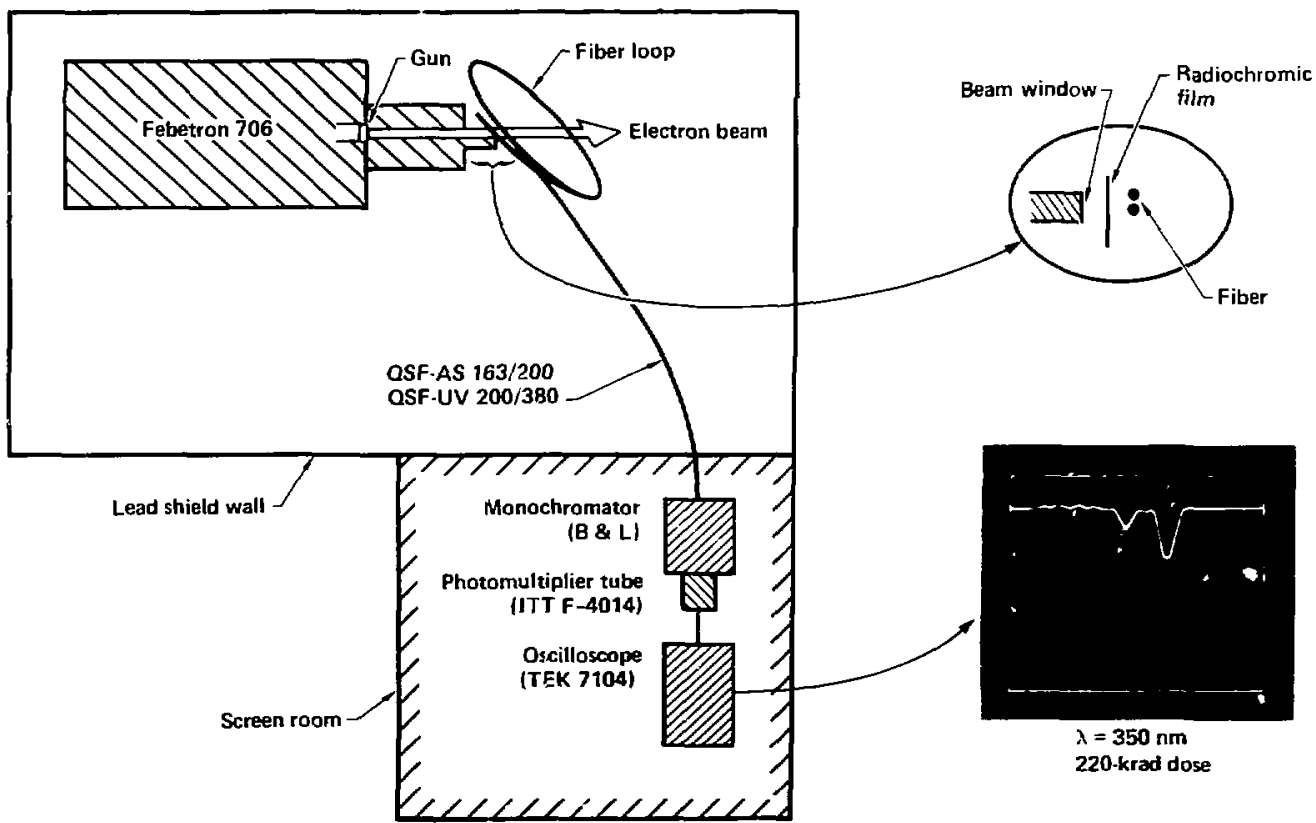

Figure 2. Experimental arrangement used to messure the suscepribility of optical fibers to radiation-induced attenuation. Cerenkov pulse's generated hy electrun-beam irradiation of sections of the fiter pased through similariy irradinted sections further down the fiber. The extent of the fiber's attenuation was determined by companing the relatise aftenuation of the pulses. Radiochromic film was used to measure the radiation dice. 


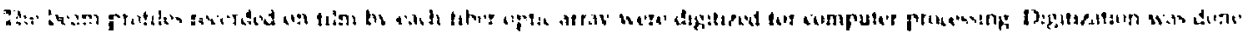

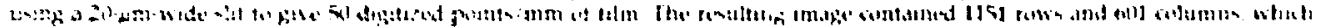

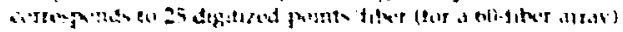

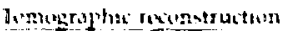

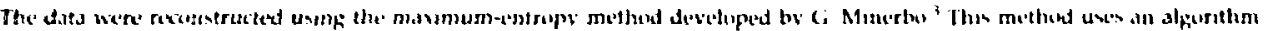

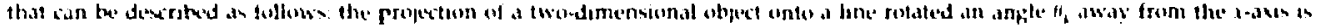
urstion a

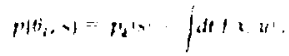

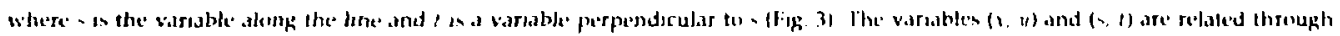

$\left(\begin{array}{l}1 \\ a\end{array}\right)=\left(\begin{array}{cc}\cos \theta_{1} & -\sin \theta_{a} \\ \sin \theta_{0} & \cos \theta_{a}\end{array}\right)\left(\begin{array}{l}-1\end{array}\right)$

and

$\left(\begin{array}{l}s \\ t\end{array}\right)=\left(\begin{array}{cc}\cos \theta_{k} & \sin \theta_{k} \\ -\sin \theta_{\alpha} & \cos \theta_{k}\end{array}\right)\left(\begin{array}{l}1 \\ y\end{array}\right)$.

The entropy of the image is defined as ${ }^{1,3}$

$H(f)=-\int d x \int d y f(x, y) \ln f(x, y)$

The algorithm attempts to maximize Eq. (4), subject to the constraints imposed by Eq. (1). This can be done through the use of La Grange multipliers. Thus the following cquation needs to be maximized:

$\left.\Psi(f, \lambda)=H(f)+\sum_{1}\left[d s\left[J_{1}, k\right)\right]-\int d t f(x, y) \mid \lambda_{t} ! s\right)$

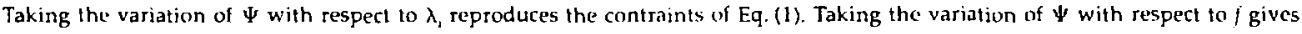

$\delta \bar{s}=\left\{-\iint d x d y(1+\ln f)-\frac{5}{s} \iint d s d t \lambda_{r}(s)\right\} \delta f=0$

or

$0=\int d x \int d y\left[1+\ln j+\sum_{1} \lambda_{1}\left(x \cos \theta_{1}+y \sin \theta_{1}\right)\right]$.

which reduces to

4

$f=c^{-1} \exp \left[-\sum_{1} \lambda_{1}\left(x \cos \theta_{1}+y \sin \theta_{1}\right)\right]$.

This can be redefined as

$f(x, y)=\prod h_{r}\left(x \cos \theta_{t}+y \sin \theta_{i}\right)$.

Returning now to Eq. (1) and substituting in Eq. (9) produces

$H_{1}(s)=\int d t \prod_{1} h_{1}\left(x \cos \theta_{t}+y \sin \theta_{t}\right)$

and using $E_{4}$. (2) gives

$P_{i}(s)=\int d t \prod\left[H_{1} \mid s \cos \left(\theta_{2}-\theta_{t}\right)+t \sin \left(\theta_{2}-\theta_{2}\right)\right]$. 


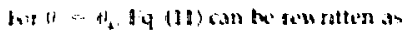

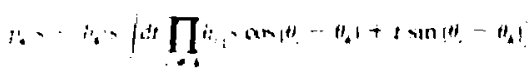

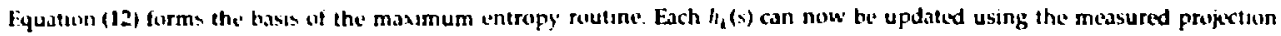
Aatu. $l_{4}(-)$, and the old valuen of $h_{1}$ as

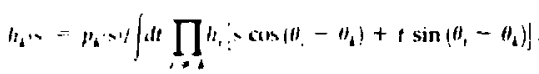

The valuse of $h_{d}(s)$ that are se determined are then used in Eq. (9) to reconstruct the image.

Data manipulations befare reconstructing

While Fys. (9) and (13) form the backbone of the maximum entropy reconstruction, two aspects of the projection data must be treated before the data is handed over the tomographic portion of the code. The first such aspect is conservation of energy. The "energy" in the image is given by

$\left.I=\int d x \int d y f x, y\right)$

This energy should also be the same as that contained in any projection or

$r=\int d s p_{k}|s|$.

This can be easily se'sn as a consequence of Eq. (1) or

$r=\int d, \mu_{i} s i=\int d s \int d f x, ! t=\int d x \int d y f(x, y)$

since buth integrals are over all space. Thus, the code finds $E$ using Eq. (15) on the first set of projection data and then normalizes each subsequent set of projection data so that it ton produces the same value of $E$.

The second aspect is that the back projection of the separate centers of mass of each set of projection data needs to meet at the center of mass (cm) of the image (Fig. 4). That this is indeed the case can be seen from the definition of the center of mass of a projection

$s_{n n_{i}}=\frac{1}{r} \int d i s p_{k} \|=\frac{1}{l} \int d s \leq \int d f(x, y)$

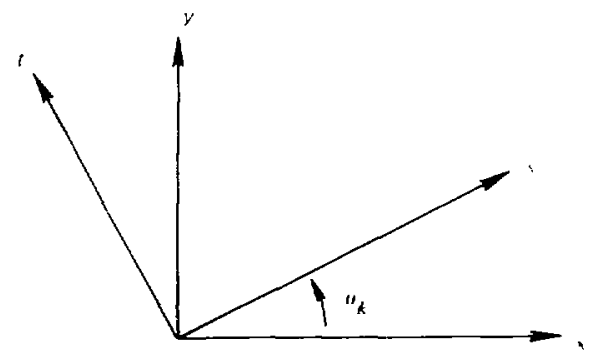

irigure 3. Relationship of reference courdinate system (x. w) to rualed comordinate sistem (s. i). The [s. : ] system was rotated by the projertion angle $\theta_{4}$. Which. in this experiment. was $a^{2}, \mathrm{n}^{\circ}$, ar 11 .

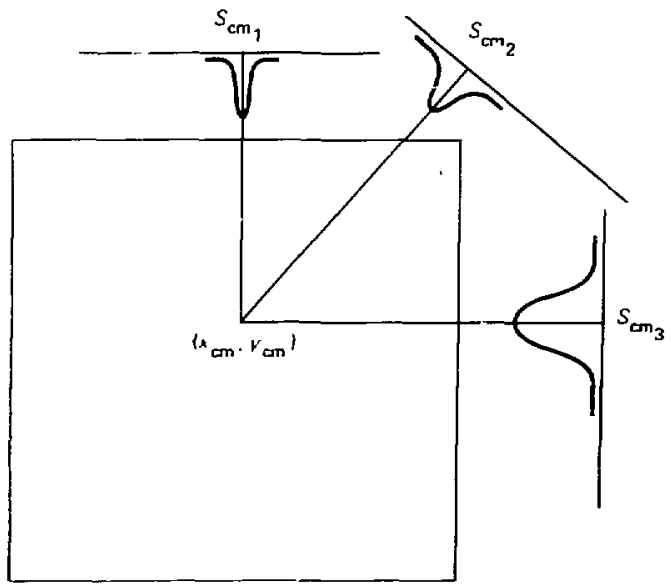

Figure 4. Hach projection of the separate centers of mass of each sel wi propetion datu, which must mox at the center of mass of the gmage. 


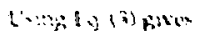

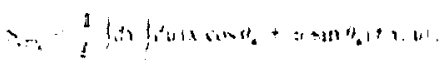

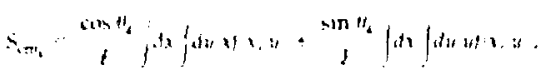

and findlls

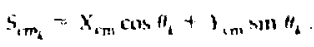

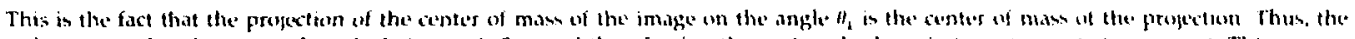

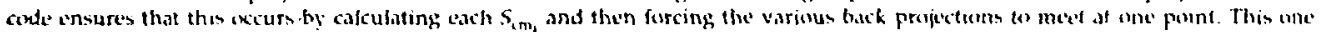

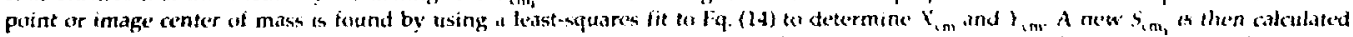

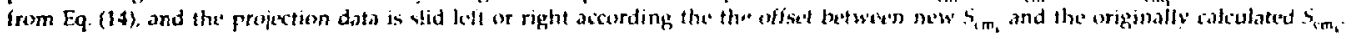

\section{Results}

Figure 5 shows conturur pluts of three digitized beam presfiles from a film recording of a 4.5-MuV. 6-kA, 30-ns FTA olectron-beam pulse through nitrogen gas at 20 Torr. The plots show that the beam wandered off the drift-tube axis during the $55-n s$ recording time. This motion was very clear in a movic of 70 reconstructed images, recorded during $55 \mathrm{~ns}$. (This off-axis propagation was also observed by two wall-current monitors placed in front and behind the tomographic arrangement along the drift tube.)

The raw data fite shown in Fig. 5 was reconstructed as follows. First, data in the y ditection betow 28.8 ns and obove 79.2 ns were ignored, thus producing a new file of 701 rows and 596 columns. Second. 70 time cuts were reconstructed to form a $70-$ frame movie showirg the evolution of the electron beam. To produce these 70 images, the file was reduced by averaging 10 rows to produce one row and averaging two columns to produce one column, thus forming a smaller file containing 70 sows and 298 columns. Third, cach filte was processed through the romographic reconstruction to produce the sequence of contour images and pseude three-dimensional images shown in Fig. 6 .

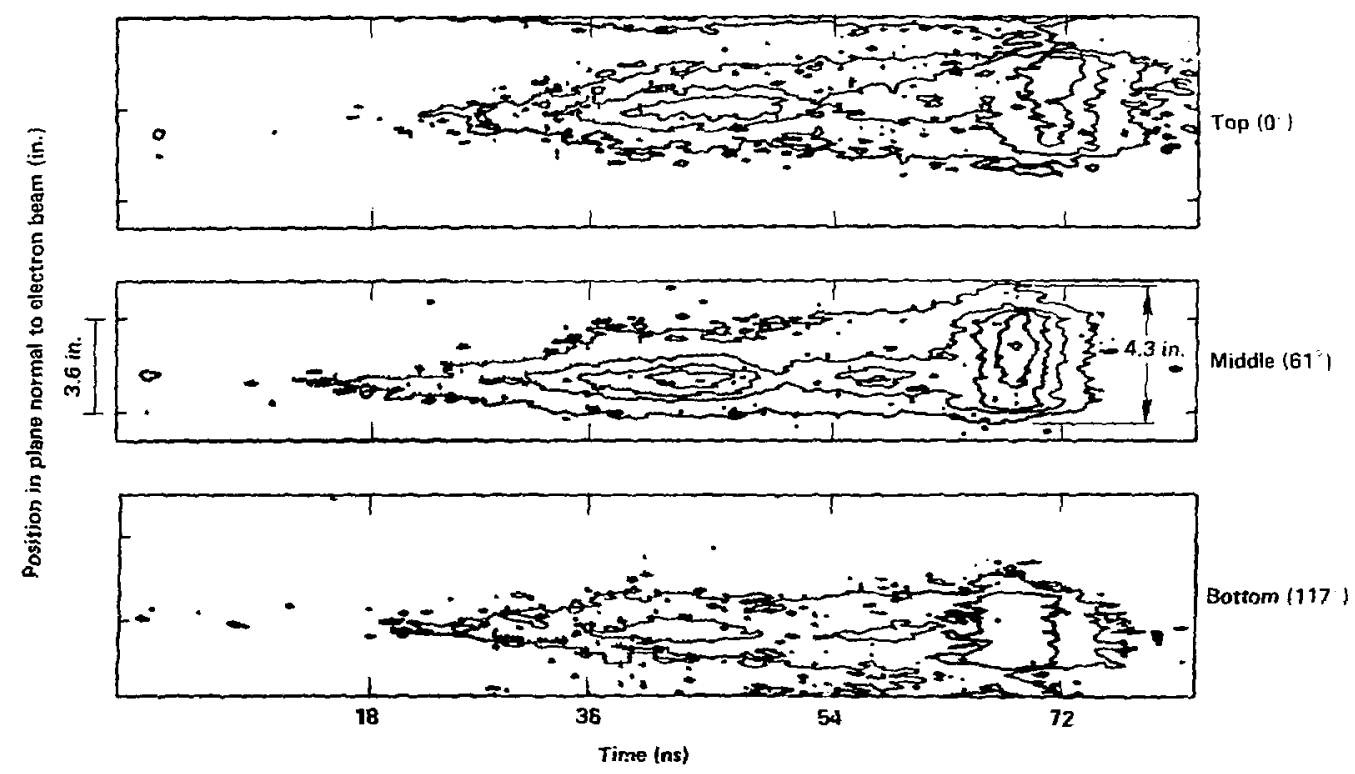

Figure 5. Contout plots of three digitized beam profiles from a film recording of a 45-MeV, 6-kA, 30-ps ET.A electron-beam puise through nitmgen gas at 20 Tors. The plots show that the bean wandered off the drift-tute axis during the 5 -iss recording time. The maximum mgion that the fibers could recond was 4.3 an. 

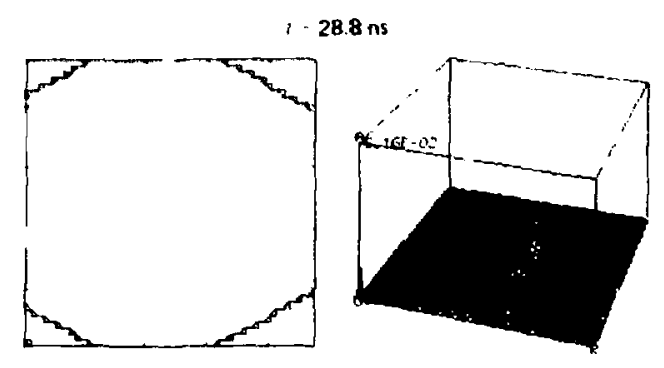

$\because$
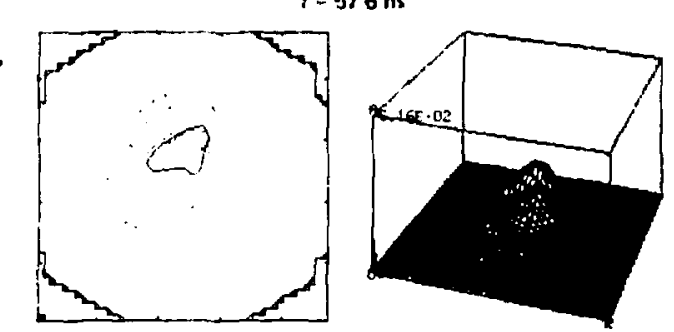

$t=36.0 \mathrm{~ns}$
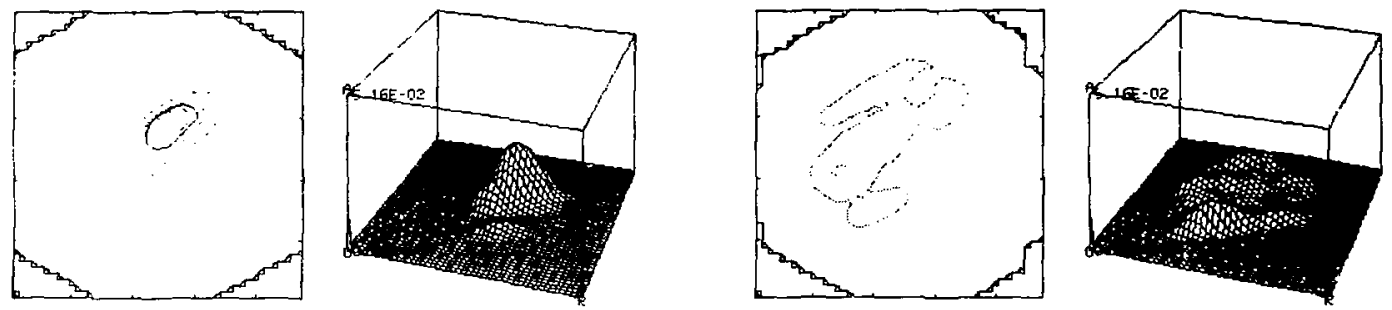

$t=43.2 \mathrm{~ns}$
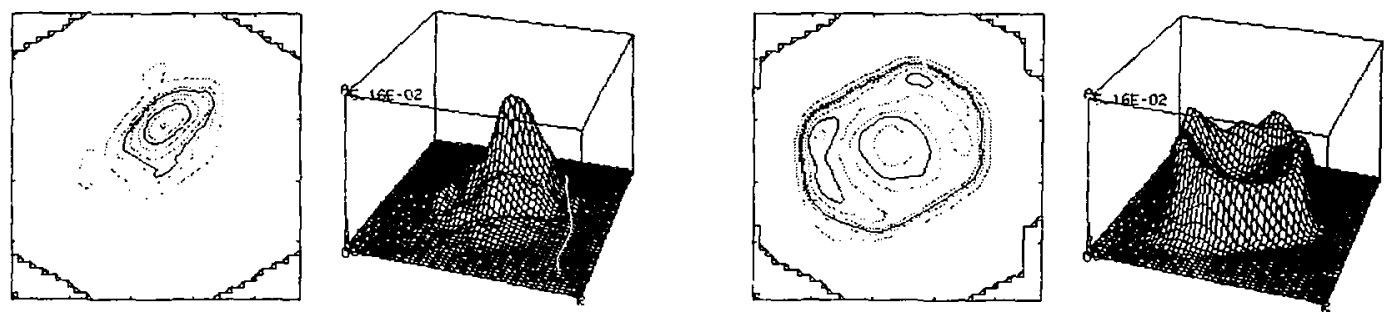

$t=50.4 \mathrm{r} / \mathrm{s}$
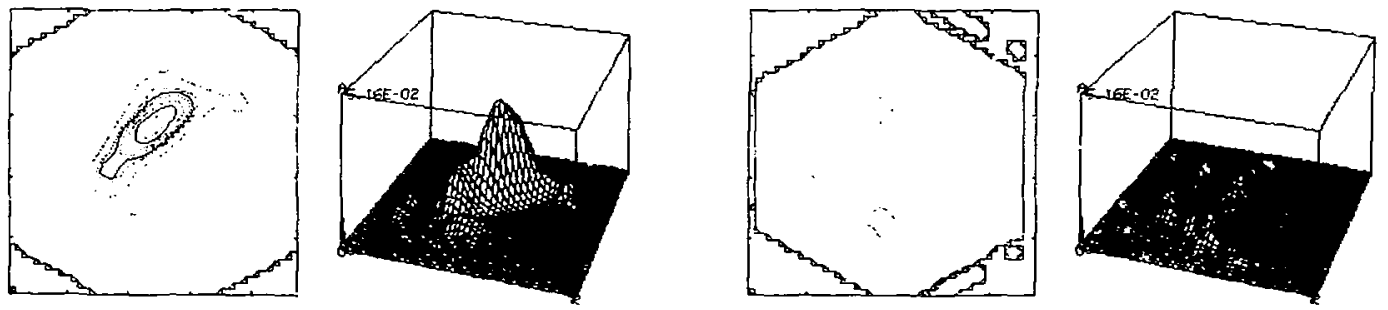

Figure 6. Sequence of contour images and puesde threedime'nsional images tom.ographically reconstructed from the data buwn in Fig. 5 . 


$$
\text { - Cinciusicts }
$$

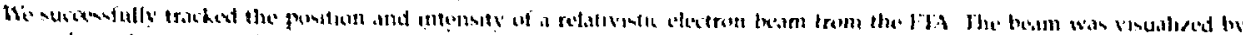

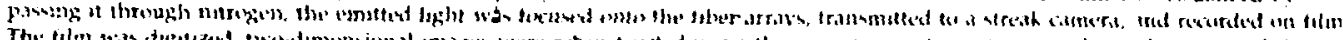

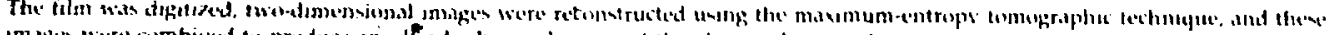

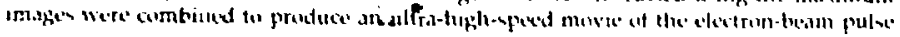

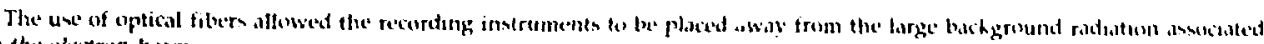
with the wextron beam.

\section{Reterences}

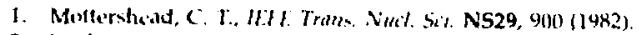

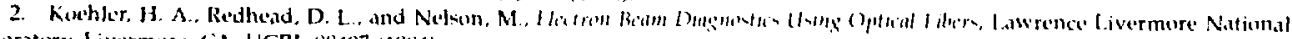
Lavoratery, Livermore, CA, UCRI.-R8497 (1984).

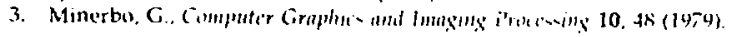

\section{DISCLAIMER}

This report was prepared as an account of work sponsored by an agency of the United States Government. Neither the United States Government nor any agency thereof, nor any of their employees, makes any warranty, express or imptizd. Or assumes any legal liability or responsibility for the accurucy, completeness, or usefulness of uny information, apparatus, product, or process disclosed, or represents that its use would not infringe privately owned rights. Relerence herein to any specilic commercial product, process, or service by trade name, trademark, manufacturer, or otherwise does not necessarily constitute or inply its endorsement. recommudation, or favoring by the United S1ates Governmem or any agency thereof. The views and opinions of authors expressed herein do noi necessarily state or reflect those of the United States Government or any agency thereot. 